\title{
Functionalized bismuth ferrite harmonic nanoparticles for cancer cells labeling and imaging
}

\author{
Solène Passemard • Davide Staedler • Giona Sonego • Thibaud Magouroux • \\ Guillaume Stéphane Schneiter • Lucienne Juillerat-Jeanneret • Luigi Bonacina • \\ Sandrine Gerber-Lemaire
}

Received: 22 July 2015/Accepted: 7 October 2015/Published online: 19 October 2015

(C) Springer Science+Business Media Dordrecht 2015

\begin{abstract}
Bismuth ferrite (BFO) harmonic nanoparticles (NPs) display high nonlinear optical efficiency and excellent biocompatibility profile which make them attractive for the development of diagnostic applications as contrast agents. In this study, we present a general method for the functionalization of this material with chemical ligands targeting cancer molecular biomarkers. In particular, a conjugation protocol based on click reaction between alkynylcontaining targeting ligands and poly(ethylene glycol)-coated BFO NPs $(67.7 \mathrm{~nm})$ displaying surface reactive azido groups was developed. Copper-free click reaction allowed fast and efficient conjugation of a covalent inhibitor of prolyl-specific endopeptidases
\end{abstract}

Electronic supplementary material The online version of this article (doi:10.1007/s11051-015-3218-8) contains supplementary material, which is available to authorized users.

S. Passemard - D. Staedler · G. Sonego ·

G. S. Schneiter · S. Gerber-Lemaire ( $\square)$

Institute of Chemical Sciences and Engineering, Ecole

Polytechnique Fédérale de Lausanne, Batochime,

1015 Lausanne, Switzerland

e-mail: Sandrine.Gerber@epfl.ch

T. Magouroux $\cdot$ L. Bonacina

GAP-Biophotonics, Université de Genève, 22 Chemin de

Pinchat, 1211 Geneva 4, Switzerland

L. Juillerat-Jeanneret

CHUV-UNIL, University Institute of Pathology,

1011 Lausanne, Switzerland to coated BFO NPs. The ability of these functionalized nanomaterials (134.2 $\mathrm{nm}$ ) to act as imaging probes for cancer cells was demonstrated by the selective labeling of human lung cancer cells.

Keywords Functionalized nanoparticles . Harmonic nanoparticles · Cancer cells targeting · Prolyl-endopeptidase inhibitors · Visualization · Nanomedicine

\section{Introduction}

Nanomaterials, and in particular nanoparticles (NPs), are being increasingly developed as contrast agents for the imaging of fundamental biological processes. Several types of materials, including silica NPs and nanocomposites (Wang and $\mathrm{Gu}$ 2015), quantum dots (Kairdolf et al. 2013), carbonaceous nanomaterials (Wen et al. 2015), semiconductor nanotubes and nanosheets (Ahmad et al. 2015), and upconversion and metal oxide NPs (Erathodiyil and Ying 2011; Zhou et al. 2015) have been widely explored for bio-imaging applications. While fluorescence/luminescence (Yao et al. 2014; Wolfbeis 2015; Chinen et al. 2015) and plasmonic response (Bardhan et al. 2011) are the most common optical properties used for imaging techniques, nonlinear optical response has only been recently demonstrated in a series of promising imaging applications. 
In this context, harmonic nanoparticles (HNPs), which are composed by non-centrosymmetric materials presenting a highly efficient nonlinear response, can be easily imaged by their second harmonic generation signal in multiphoton imaging setups (Bonacina 2012; Cohen 2010; Pantazis et al. 2010; Meyer et al. 2013). In contrast with most nanophotonic probes for bio-imaging applications which are based on static optical properties, HNPs can fully exploit the tuning capabilities offered by new laser sources (from 400 to $1550 \mathrm{~nm}$ ). In addition, despite their lower brightness compared to fluorescence imaging labels, HNPs present many favorable properties for optical imaging, including the absence of photobleaching and blinking (Le Xuan et al. 2008), no specific wavelength dependence allowing excitation from UV to IR (Extermann et al. 2009), and fully coherent response and narrow emission signals (Baumner et al. 2010; Hsieh et al. 2010a, b). These unique features combined in a single optical probe have been recently reported for cell, tissue, and in vivo imaging applications (Čulić-Viskota et al. 2012, Dempsey et al. 2012, Magouroux et al. 2012).

Various types of HNPs, mainly metal oxide materials, have been produced and characterized, such as barium titanate $\left(\mathrm{BaTiO}_{3}\right)$, iron iodate $\left(\mathrm{Fe}\left(\mathrm{IO}_{3}\right)_{3}\right)$, lithium niobate $\left(\mathrm{LiNbO}_{3}\right)$, potassium niobate $\left(\mathrm{KNbO}_{3}\right)$, potassium titanyl phosphate $(\mathrm{KTP})$, and zinc oxide $(\mathrm{ZnO})$. In a comprehensive study, we demonstrated that these nanoparticles display efficient harmonic conversion and low cytotoxicity with the exception of $\mathrm{ZnO}$ materials (Staedler et al. 2012). More recently, bismuth ferrite nanoparticles $\left(\mathrm{BiFeO}_{3}\right.$, abbreviated as BFO NPs) were introduced as promising nonlinear optical probes due to their very high second harmonic efficiency which was demonstrated to be one order of magnitude higher than for standard harmonic nanomaterials (Schwung et al. 2014). In addition, we gave evidence for the good biocompatibility of PEGylated BFO NPs (Staedler et al. 2015) and for the ability of BFO NPs to locally induce DNA damage by deep UV generation (Staedler et al. 2014). In view of the favorable profile of these HNPs for bioimaging applications, their functionalization with targeting entities was envisaged for the development of nanoprobes for cancer cells labeling. Different types of targeting agents, including antibodies, peptides, and small molecules have been conjugated to inorganic NPs for the detection of cancer molecular biomarkers. Antibodies offer high affinity and selectivity to the resulting conjugates, but may alter the permeability of NPs across the vasculature and the blood vessel walls as they considerably increase the size of the NPs (Arruebo et al. 2009). Antibody-NPs conjugates may also induce adverse immune response over prolonged use. Therefore, surface modification of BFO NPs with low molecular weight targeting ligands appears as an appealing strategy for the detection of cancer cells (Sun et al. 2006).

We report herein a functionalization methodology for the conjugation of PEGylated BFO NPs to cancertargeting ligands based on azide-alkyne [3+2] cycloaddition (click reaction), catalyzed by copper (I) species (Rostovtsev et al. 2002) or promoted by the use of strained cyclooctynes (Sletten and Bertozzi 2011). In particular, the cyclic Arg-Gly-Asp (RGD) peptide derivative cRGDfK, a ligand for the $\alpha_{\mathrm{v}} \beta_{3}$ integrin (Danhier et al. 2012), and a specific inhibitor of prolyl-endopeptidases (Juillerat-Jeanneret and Gerber-Lemaire 2009; Brennen et al. 2012), respectively, were covalently associated to the nanoparticles surface for recognition of the cancer cells and cancer associated-cell membrane molecular biomarkers. The resulting cancer-targeting NPs have been characterized and evaluated for their ability to label human lung cancer cells.

\section{Materials and methods}

Chemical syntheses—general conditions

Commercial reagents (Fluka, Aldrich, TCI, Switzerland) were used without further purification. Unless special mention, all reactions were performed under argon atmosphere $(1 \mathrm{~atm})$. Anhydrous solvents were obtained by filtration (Innovative Technology, Oldham, UK). Reactions were monitored by TLC (Merck silica gel 60F254 plates, Merck, Darmstadt, Germany). Detection was performed by UV light, $\mathrm{KMnO}_{4}$, Ninhydrin, or $\mathrm{I}_{2}$. Purifications were performed by flash chromatography on silica gel (Merck $\mathrm{N}^{\circ} 9385$ silica gel 60, 240-400 mesh). IR spectra were recorded on a Perkin-Elmer-1420 spectrometer (Perkin-Elmer, Waltham, MA, USA). ${ }^{1} \mathrm{H}$ NMR spectra were recorded on a Bruker ARX-400 spectrometer (400 MHz) (Bruker, Billerica, MA, USA). ${ }^{13} \mathrm{C}$ NMR spectra were recorded on a Bruker ARX-400 
spectrometer (100.6 MHz). Chemical shifts are expressed in parts per million (ppm) and coupling constants $(J)$ in hertz. Solvents used for NMR spectroscopy are deuterated chloroform $\left(\mathrm{CDCl}_{3}\right.$, Acros) and deuterated methanol $\left(\mathrm{CD}_{3} \mathrm{OD}\right.$, Acros). Mass spectra were obtained on a Nermag R-10-10C spectrometer with chemical ionization $\left(\mathrm{NH}_{3}\right)$ and mode $\mathrm{m} / \mathrm{z}$ (amu) [\% relative base peak $(100 \%)$ ] (Nermag, Santa Clara, CA, USA). Semi-preparative HPLC was performed on a Waters Autopurification ZQ System equipped with a 2767 Sample Manager, a 2525 Binary Gradient Module, and a 2996 Photodiode Array Detector, coupled to Waters Micromass ZQ analyzer. The HPLC purifications were performed on XTerra Prep RP C18 $(19 \times 150 \mathrm{~mm})$ columns, using reverse-phase conditions ( 2 to $100 \%$ acetonitrile with $0.1 \%$ TFA over $20 \mathrm{~min}$ ). Measurements of the dynamic light scattering and zeta potential were obtained using a Malvern NanoZ instrument (Malvern Instruments, Malvern, UK).

Synthesis of targeting ligands (Scheme 2)

Synthesis of tert-butyl [(3-oxo-1,2-dihydro- $1 \mathrm{H}$ isoindol-5-yl)oxy]acetate (4)

To a solution of $\mathbf{3}(6.13 \mathrm{mmol}, 1.0 \mathrm{~g})$ in $\mathrm{CH}_{3} \mathrm{SO}_{3} \mathrm{H}(20$ equiv, $7.96 \mathrm{~mL}$ ) was added methionine (1.8 equiv, $11.04 \mathrm{mmol}, 1.64 \mathrm{~g}$ ) and the mixture was stirred at $85{ }^{\circ} \mathrm{C}$ for $16 \mathrm{~h}$. After cooling to $25^{\circ} \mathrm{C}$, cold water $\left(5{ }^{\circ} \mathrm{C}\right)$ was added, and the mixture was maintained at $5{ }^{\circ} \mathrm{C}$ for $1 \mathrm{~h}$. The solid was recovered by filtration, washed with water containing aqueous $1 \% \mathrm{HCl}$, and then dried to afford the intermediate phenol $(664 \mathrm{mg}$, $73 \%$ ) as a white solid. To a solution of this intermediate $(11.4 \mathrm{mmol}, 1.7 \mathrm{~g})$ in $\mathrm{N}, \mathrm{N}$-dimethylformamide (DMF)/dichloromethane (DCM) $(1: 1,20 \mathrm{~mL})$, were added tert-butyl bromoacetate $(11.97 \mathrm{mmol}, 3.11 \mathrm{~g}$, $2.35 \mathrm{~mL}), \mathrm{Bu}_{4} \mathrm{NBr}(0.57 \mathrm{mmol}, 184 \mathrm{mg})$, and $50 \%$ aqueous $\mathrm{NaOH}$ (11.97 mmol, $479 \mathrm{mg}$ ). The mixture was stirred for $16 \mathrm{~h}$ at $25^{\circ} \mathrm{C}$ and the product was extracted with DCM $(20 \mathrm{~mL})$. The organic layer was dried $\left(\mathrm{MgSO}_{4}\right)$ and concentrated in vacuo. Purification by flash chromatography (petroleum ether (PE)/EtOAc 1:1) gave 4 as a white solid $(1.88 \mathrm{~g}, 62 \%)$. ESIHRMS: calcd for $\mathrm{C}_{14} \mathrm{H}_{17} \mathrm{NO}_{4}$ : 264.1236; found:
264.1244. ${ }^{1} \mathrm{H},{ }^{13} \mathrm{C}$ NMR, and IR spectral description are given in supporting information.

Synthesis of (S)-tert-butyl 2-((2-(2-(2-

cyanopyrrolidin-1-yl)-2-oxoethyl)-3-oxoisoindolin-5yl)oxy)acetate (6)

$1 \mathrm{M}$ Lithium bis(trimethylsilyl)amide (LiHMDS) in tetrahydrofuran (THF) $(615 \mu \mathrm{mol}, 615 \mu \mathrm{L})$ was added to a cooled $\left(0{ }^{\circ} \mathrm{C}\right)$ solution of $\mathbf{4}(410 \mu \mathrm{mol}, 107 \mathrm{mg})$ in THF $(1.2 \mathrm{~mL})$. After $30 \mathrm{~min}$, a solution of $\mathbf{5}$ $(529 \mu \mathrm{mol}, 115 \mathrm{mg})$ in THF $(1.2 \mathrm{~mL})$ was added dropwise. The mixture was slowly warmed to $25^{\circ} \mathrm{C}$ and was stirred for $10 \mathrm{~h}$. Completion of the reaction was monitored by thin-layer chromatography (TLC) and ESI-MS. Volatiles were removed in vacuo. The crude residue was purified by flash chromatography (DCM, then DCM/MeOH 60: 1) to afford 6 as a transparent oil (0.120 g, $73 \%)$. ESI-HRMS: calcd for $\mathrm{C}_{21} \mathrm{H}_{25} \mathrm{~N}_{3} \mathrm{O}_{5}$ : 400.1873; found: 400.1886. ${ }^{1} \mathrm{H},{ }^{13} \mathrm{C}$ $\mathrm{NMR}$, and IR spectral description are given in supporting information.

\section{Synthesis of ligand 2}

Compound 6 (1.25 mmol, $500 \mathrm{mg}$ ) was added to a suspension of silica $(6.25 \mathrm{~g})$ in toluene $(25 \mathrm{~mL})$. The mixture was refluxed for $1.5 \mathrm{~h}$ under vigorous stirring. The mixture was diluted in DCM/MeOH 4:1 and Celite was added. The mixture was filtered. The pad of Celite was washed with $\mathrm{DCM} / \mathrm{MeOH} 4: 1$ and the combined filtrates were evaporated under reduced pressure to obtain free carboxylic acid intermediate as a white solid (quant.). To this compound (131 $\mu \mathrm{mol}$, $45 \mathrm{mg})$ in DMF $(1 \mathrm{~mL})$ were added compound 7 (137 $\mu \mathrm{mol}, \quad 60 \mathrm{mg}), \quad$ 1-ethyl-3-(3-dimethylaminopropyl)carbodiimide (EDCI) $(222 \mu \mathrm{mol}, 43 \mathrm{mg})$, 1-hydroxybenzotriazole (HOBt) $(170.3 \mu \mathrm{mol}, 23 \mathrm{mg})$, and $\left({ }^{i} \operatorname{Pr}\right)_{2} \mathrm{NEt}(393 \mu \mathrm{mol}, 50.8 \mathrm{mg}, 65 \mu \mathrm{L})$. The reaction mixture was stirred for $12 \mathrm{~h}$ at $25{ }^{\circ} \mathrm{C}$. DMF was evaporated and the product was purified by flash chromatography (DCM/MeOH 25:1) to afford 2 as a colorless oil (98 $\mu \mathrm{mol}, 75 \mathrm{mg}, 75 \%)$. ESI-HRMS: calcd. for $\mathrm{C}_{42} \mathrm{H}_{45} \mathrm{~N}_{5} \mathrm{O}_{9}$ : 764.3295; found: 764.3293. ${ }^{1} \mathrm{H},{ }^{13} \mathrm{C}$ NMR, and IR spectral description are given in supporting information. 
Functionalization of BFO NPs (Scheme 3)

\section{Functionalization of PEG-BFO NPs with ligand 1}

To a suspension of PEG-BFO NPs (6 mg) in EtOH $(1 \mathrm{~mL})$ was added distilled water $(2 \mathrm{~mL})$ and $\mathbf{1}(4 \mathrm{mg}$, dissolved in $100 \mu \mathrm{L}$ of DMF). $\mathrm{CuSO}_{4}(2 \mathrm{mg})$ and sodium ascorbate $(2 \mathrm{mg}$ ) were added and the suspension was ultra-sonicated for $12 \mathrm{~h}$ at $40{ }^{\circ} \mathrm{C} .1,4,8,11$ Tetraazacyclotetradecane (Cyclam) (10 mg) was added and the suspension was dialyzed against a solution of dodecyltrimethylammonium bromide in distilled water $(0.1 \mathrm{M}, 2 \mathrm{~mL})$ for $24 \mathrm{~h}$ followed by dialysis against distilled water $(3 \times 24 \mathrm{~h})$. fNP-1 were concentrated and suspended in EtOH $(1 \mathrm{~mL})$.

\section{Functionalization of PEG-BFO NPs with ligand 2}

To a suspension of PEG-BFO NPs $(5.5 \mathrm{mg})$ in EtOH $(1 \mathrm{~mL})$ were added distilled water $(5 \mathrm{~mL})$ and 2 (13 $\mu \mathrm{mol}, 10 \mathrm{mg}$, dissolved in $750 \mu \mathrm{L}$ of DMF). The suspension was ultra-sonicated for $12 \mathrm{~h}$ at $40{ }^{\circ} \mathrm{C}$. The suspension was washed with toluene $(3 \times 5 \mathrm{~mL})$ and organic layers were washed with water. Combined aqueous layers were evaporated and co-evaporated with toluene in vacuo. The resulting fNP-2 were suspended in EtOH $(1 \mathrm{~mL})$.

Characterization of functionalized BFO NPs: DLS and zeta potential measurement

A suspension of coated or functionalized NPs $(20 \mu \mathrm{L})$ was diluted with distilled $\mathrm{H}_{2} \mathrm{O}(1 \mathrm{~mL})$ and $\mathrm{AcOH}(100$ $\mu \mathrm{L})$ was added. The resulting suspension was ultrasonicated for $5 \mathrm{~min}$ and washed 3 times with distilled $\mathrm{H}_{2} \mathrm{O}(1 \mathrm{~mL})$. NPs were suspended in distilled water $(1 \mathrm{~mL})$ and sonicated for $30 \mathrm{~min}$. The sizes and surface charges of the resulting suspensions were analyzed with a Malvern NanoZ instrument (Malvern Instruments, Malvern, UK).

Inhibition of human recombinant enzyme by compound $\mathbf{8}$

The human recombinant enzymes were obtained from hrDPPIV (Enzo Life Sciences, Lausen, Switzerland), hrFAP $\alpha$ (R\&D systems, Abingdon, UK), and hrPOP/ PREP (Enzo Life Sciences). The enzymatic activity was measured in flat bottom 96-well plates (Costar,
Corning, NY, USA) containing in each well $0.01 \mu \mathrm{g}$ of the enzymes and $50 \mu \mathrm{M}$ of substrate (Z-Gly-Pro-AMC for hrFAP $\alpha$ and hrPOP, and H-Gly-Pro-AMC for hrDPPIV, both substrates from Bachem) diluted in their respective assay buffers (50 $\mathrm{mM}$ Tris, $1 \mathrm{M} \mathrm{NaCl}$ and $1 \mathrm{mg} / \mathrm{mL}$ bovin serum albumin (BSA), $\mathrm{pH} 7.5$, for $\mathrm{hrFAP} \alpha ; 50 \mathrm{mM}$ Tris and $1 \mathrm{mg} / \mathrm{mL}$ BSA, $\mathrm{pH}$ 7.5, for hrPOP; $25 \mathrm{mM}$ Tris and $1 \mathrm{mg} / \mathrm{mL}$ BSA, $\mathrm{pH} 8.0$ for hrDPPIV; all reagents from Sigma-Aldrich, Buchs, Switzerland). The enzyme solutions were incubated for $30 \mathrm{~min}$ with increasing concentrations $(5,10,50$, 200, 500, 1000, 5000, and $10000 \mathrm{nM}$ ) of compound $\mathbf{8}$. Then inhibition was determined by evaluation of the residual enzymatic activity: measurement of the fluorescence increase for $1 \mathrm{~h}$ at $37^{\circ} \mathrm{C}$ in a fluorescence multi-well plate reader $\left(\lambda_{\mathrm{ex}} / \lambda_{\mathrm{em}}=360 / 460 \mathrm{~nm}\right.$, Synergy HT, BioTek, Winooski, VT, USA). Experiments were conducted in triplicate wells and repeated twice. $\mathrm{IC}_{50}$ and $\mathrm{K}_{i}$ were calculated according to Cer et al. (2009).

Cells and cell culture conditions

A549, BEAS-2B, NCI-H596, and NCI-H520 cell lines are available from ATCC (American Tissue Culture Collection, Manassas, VA, USA). A549 and BEAS2B cells were grown in Dulbecco's Modified Eagle Medium (DMEM) medium containing $4.5 \mathrm{~g} / \mathrm{L}$ glucose, $10 \%$ heat-inactivated fetal calf serum (FCS), and penicillin/streptomycin (all cell culture reagents were obtained from Invitrogen, Basel, Switzerland). NCI-H596 cells were grown in complete Roswell Park Memorial Institute (RPMI) 1640 medium (Invitrogen) supplemented with $20 \%$ FCS and penicillin/streptomycin. NCI-H520 cells were grown in RPMI 1640 medium supplemented with $10 \%$ FCS and penicillin/ streptomycin.

Detection of the association of compound $\mathbf{8}$ with cells

The cells were grown for $48 \mathrm{~h}$ in BD Falcon CultureSlides (BD Biosciences, Erembodegem, Belgium), then the cell layers were washed with Hank's Balanced Salt Solution (HBSS) at $37{ }^{\circ} \mathrm{C}$, exposed to $100 \mu \mathrm{M}$ of compound 8 or to vehicle (dimethyl sulfoxide (DMSO)), $0.5 \%$ final concentration in HBSS for $30 \mathrm{~min}$ at $37^{\circ} \mathrm{C}$. Cell layers were washed twice with HBSS and fixed with $4 \%$ formaldehyde in 
PBS for $30 \mathrm{~min}$ at $5{ }^{\circ} \mathrm{C}$. The fixed cell layers were blocked for $1 \mathrm{~h}$ with $1 \%$ BSA in PBS (phosphatebuffered saline) at room temperature, then washed and exposed to horseradish peroxidase (HRP)-conjugated streptavidin (Merck) diluted 1:100 in antibody diluent (Dako, Baar, Switzerland). HRP activity was revealed using the DAB + CHROMOGEN $^{\mathrm{TM}}$ system from Dako, according to the supplier instructions. Finally, the cell layers were counterstained with hematoxylin and images were taken using a transmitted light microscope (DM IL LED from Leica, Renens, Switzerland) equipped with a digital camera (ICC50HD, Leica).

Inhibition of prolyl-oligopeptidase activities in living cells

The cells (50'000 cells/well) were grown for $24 \mathrm{~h}$ in flat bottom 96-well plates (Corning), then were exposed to increasing concentrations $(5,10$, and $20 \mu \mathrm{M}$ ) of compound 8 and to $50 \mu \mathrm{M}$ of Z-Gly-Pro7-amino-4-methylcoumarin (AMC) (for prolyl-endopeptidase activity) or $50 \mu \mathrm{M}$ of H-Gly-Pro-AMC (for prolyl-exopeptidase activity) (Bachem, Vionnaz, Switzerland). Fluorescence increase was measured for $1 \mathrm{~h}$ at $37{ }^{\circ} \mathrm{C}$ in a fluorescence multi-well plate reader (Synergy HT) at $\lambda_{\mathrm{ex}} / \lambda_{\mathrm{em}}=360 / 460 \mathrm{~nm}$. Experiments were conducted in triplicate wells and repeated twice. Means \pm standard deviations were calculated.

Detection of the association between compound $\mathbf{8}$ and cells

The cells were grown for $48 \mathrm{~h}$ in BD Falcon CultureSlides (BD Biosciences), then the cell layers were exposed to vehicle (DMSO) or to compound $\mathbf{8}$ at the indicated time and concentrations in cell medium at $37{ }^{\circ} \mathrm{C}$. After the incubation time, the cell layers were fixed with $4 \%$ formaldehyde in PBS for $30 \mathrm{~min}$ at $5{ }^{\circ} \mathrm{C}$. Fixed cells were then washed with PBS, permeabilized $5 \mathrm{~min}$ in $0.1 \%$ Triton X-100 (SigmaAldrich) in PBS, incubated $10 \mathrm{~min}$ at $25{ }^{\circ} \mathrm{C}$ in $3 \%$ $\mathrm{H}_{2} \mathrm{O}_{2}$ in methanol, and blocked $2 \mathrm{~h}$ with $1 \% \mathrm{BSA}$ in PBS at $25{ }^{\circ} \mathrm{C}$, then washed and exposed for $90 \mathrm{~min}$ to HRP-conjugated streptavidin (Merck) diluted 1:100 in antibody diluent (Dako). HRP activity was revealed using the DAB + CHROMOGENTM system from Dako, according to the supplier instructions. Finally, the cells were counterstained with hematoxylin and images were taken using a transmitted light microscope (DM IL LED from Leica) equipped with a digital camera (ICC50HD, Leica).

Multiphoton imaging of the association between fNP-2 and cells

Cells were grown on round-shaped microscope coverslips (BD Falcon) for $24 \mathrm{~h}$ in a 24-well plate (Corning) then the cell layers were washed with HBSS at $37^{\circ} \mathrm{C}$ and exposed to the coated and functionalized NPs at indicated concentrations or to vehicle (ethanol, $1 \%$ final concentration) in $500 \mu \mathrm{L}$ HBSS for indicated time at $37{ }^{\circ} \mathrm{C}$. The cell layers were washed twice with HBSS and fixed in $4 \%$ formaldehyde in PBS for $30 \mathrm{~min}$ at $5{ }^{\circ} \mathrm{C}$. After fixation, the cells were labeled with fluorescent probes.

For imaging, a multiphoton inverted microscope (Nikon A1R-MP) coupled with a tunable Ti:Sapphire oscillator (Spectra-Physics Mai-Tai, $100 \mathrm{fs}, 80 \mathrm{MHz}$, $700-1000 \mathrm{~nm}$ ) was used. A $20 \times$ N.A. 0.75 objective was used to focus the excitation laser and to epi-collect the SHG signal from the nanoparticles and dye markers fluorescence. Typical average power at the sample: $3 \mathrm{~mW}$.

\section{Results and discussion}

Efficient surface functionalization of BFO NPs is of high importance for bio-imaging applications, in particular for targeted imaging of cancer cells and earlystage tumors. We decided to explore the conjugation of targeting entities by click reaction between PEGylated BFO NPs displaying surface reactive azido groups and alkynyl-containing ligands designed for recognition of molecular cancer biomarkers (Scheme 1). $\alpha_{\mathrm{v}} \beta_{3}$ Integrin is a well-established target for cancer diagnosis (Desgrosellier and Cheresh 2010) and can be efficiently bound by cyclic RGD peptides and RGD peptidomimetics. Prolyl-oligopeptidases, in particular the serine proteases FAP $\alpha$ which exhibits both exopeptidase and endoproteolytic activity, and prolyl-oligopeptidase (POP) which is restricted to endoproteolytic cleavages, have been associated with the development of cancers and other diseases (Brennen et al. 2012; Lawandi et al. 2010). Covalent inhibitors based on previously reported N-blocked boroPro inhibitors (Poplawski et al. 2013) 


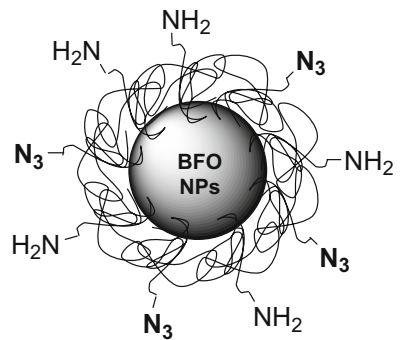

PEG-BFO NPs

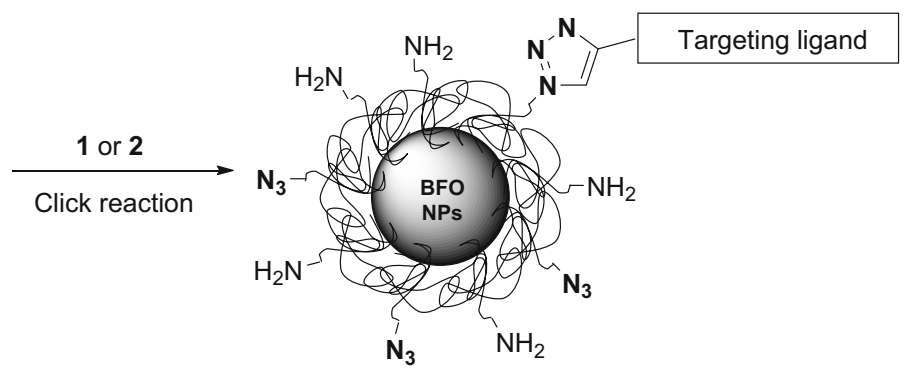

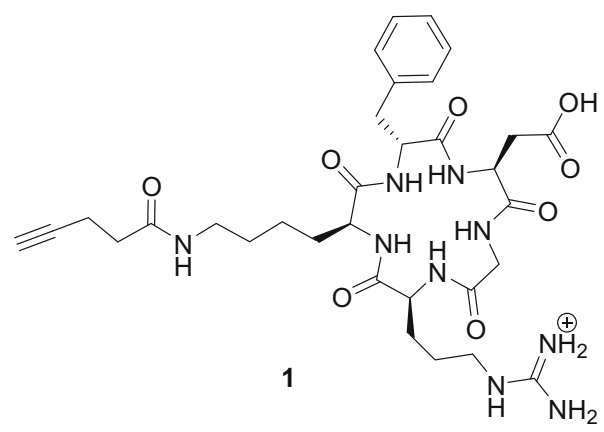

Targeting $\alpha v \beta 3$ integrin

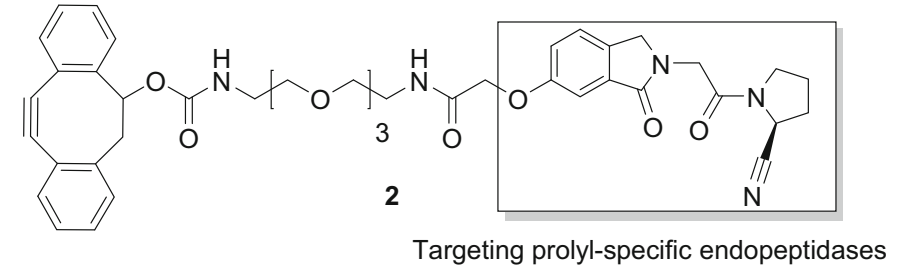

Targeting prolyl-specific endopeptidases

Scheme 1 Functionalization of BFO NPs for cancer cells labeling

can thus be developed for the labeling of malignant cells and tumor-associated cells expressing these enzymes.

Our strategy relies on the conjugation of PEGylated BFO NPs with ligands $\mathbf{1}$ and $\mathbf{2}$ as model compounds for the targeting of $\alpha_{\mathrm{v}} \beta_{3}$ integrin and prolyl-specific endopeptidases expressed by cancer- and tumorassociated cells.

Synthesis of targeting ligands for conjugation to harmonic NPs

Ligand 1 resulted from the coupling of cRGDfK, prepared by solid-phase peptide synthesis (Borcard et al. 2012), with activated ester of pentynoic acid as previously reported (Passemard et al. 2013). Preparation of ligand $\mathbf{2}$ started by cleavage of the methyl ether from isoindolinone $\mathbf{3}$ (prepared according to Powers et al. 2009) followed by subsequent O-alkylation of the corresponding phenol with tert-butyl bromoacetate to afford compound 4 in $45 \%$ yield. Deprotonation of the lactam moiety followed by condensation with cyano-proline derivative $\mathbf{5}$ (synthesis described in supporting information) delivered the core of the targeting agent (6) in $73 \%$ yield. Further derivatization with a cyclooctyne moiety was performed by coupling with compound 7 (synthesis described in supporting information) to provide the targeting ligand 2, ready to be conjugated to PEGylated BFO NPs. To assess the targeting ability of this ligand toward prolyl-specific endopeptidases in cancer cell lines, functionalization with a biotin label was also performed and delivered compound $\mathbf{8}$ (Scheme 2).

Functionalization of BFO NPs with targeting ligand $\mathbf{1}$ and $\mathbf{2}$

Starting suspension of BFO NPs (62.5 wt $\%$ in $\mathrm{ZrO}_{2}$ balls, provided by the company FEE (Germany)) was first converted into a stock polydisperse suspension at $3.6 \mathrm{mg} / \mathrm{mL}$ (particle size: $128.8 \pm 11.2 \mathrm{~nm}$ ), and then converted into PEGylated nanoparticles (PEG-BFO NPs, particle size: $67.7 \pm 5.6 \mathrm{~nm}$ ), according to a protocol previously described in our group (Staedler et al. 2015) (detailed protocol and characterization is provided in supporting information). Based on recent efforts toward the development of efficient functionalization pathways for metal oxide NPs (Passemard et al. 2013), PEG-BFO NPs displaying surface azido and amino functionalities were suspended in distilled water and subjected to $[3+2]$-cycloaddition with 


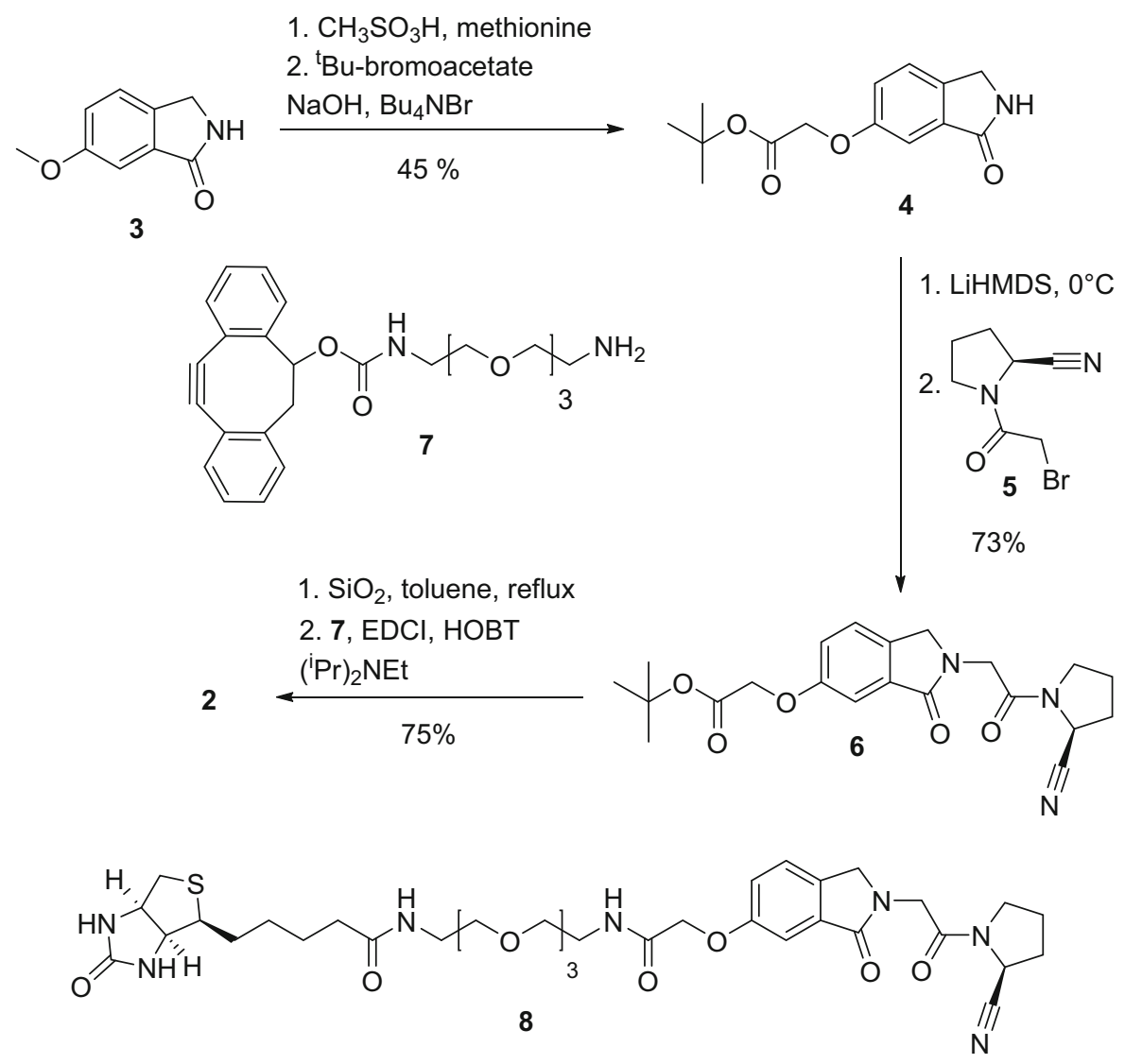

Scheme 2 Synthesis of targeting ligands for further conjugation to harmonic NPs

ligand 1, in the presence of copper sulfate and sodium ascorbate (Scheme 3). Ultrasonication for $12 \mathrm{~h}$ followed by removal of copper species by treatment with Cyclam and purification by dialysis afforded BFO NPs conjugated to the ligand targeting $\alpha_{v} \beta_{3}$ integrin (fNP1). Alternatively, treatment of PEG-BFO NPs with ligand 2 allowed conjugation by copper-free click reaction to afford fNP-2, which were purified by simple washing with toluene to remove unreacted ligand.

Surface functionalization of PEG-BFO NPs was monitored by FT-IR (Fig. 1). The formation of the resulting triazole moieties was evidenced by apparition of a C-N stretching band at 1320 (fNP-1) and 1390 (fNP-2) $\mathrm{cm}^{-1}$. Presence of the peptide ligand in fNP-1 was indicated by amide stretching bands at 1650 and $1570 \mathrm{~cm}^{-1}$, while nitrile stretching band at $2320 \mathrm{~cm}^{-1}$ supported conjugation of targeting ligand 2 to PEG-BFO NPs.
The coated and functionalized NPs were characterized for their size and surface charge by measurement of the mean hydrodynamic diameter (Dynamic Light Scattering, DLS) and zeta potential (detailed characterization is provided in supporting information). Upon functionalization, the hydrodynamic diameter of harmonic NPs shifted from $67.7 \pm$ $5.6 \mathrm{~nm}$ (PEG-BFO NP) to $141.8 \pm 0 \mathrm{~nm}$ for fNP-1 and to $134.2 \pm 11.5 \mathrm{~nm}$ for $\mathbf{f N P}-\mathbf{2}$. The zeta potential value increased from $-2.3 \pm 0.4 \mathrm{mV}$ (PEG-BFO NP) to $+17.3 \pm 0.3 \mathrm{mV}$ (fNP-1) and $+0.7 \pm 0.9 \mathrm{mV}$ (fNP-2).

Targeting ability of functionalized harmonic NPs and cancer cells labeling

The first cellular assays performed with fNP-1 revealed the presence of traces of residual copper species which resulted in cytotoxic effects on studied 


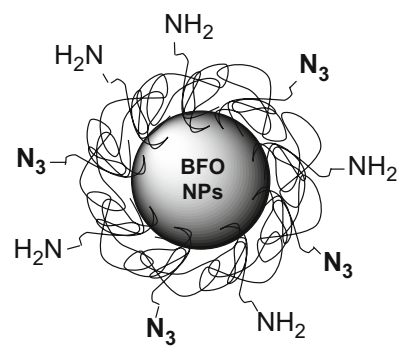

PEG-BFO NPs
1. $1, \mathrm{CuSO}_{4}$ sodium ascorbate ultrasonication

2. Cyclam 2, ultrasonication

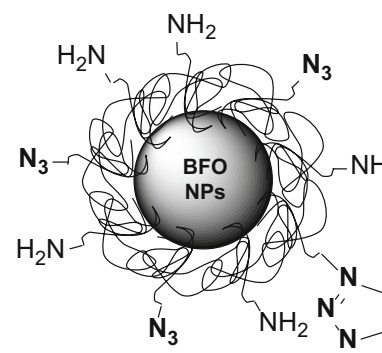

fNP-2

Scheme 3 Functionalization of BFO harmonic NPs by click reaction

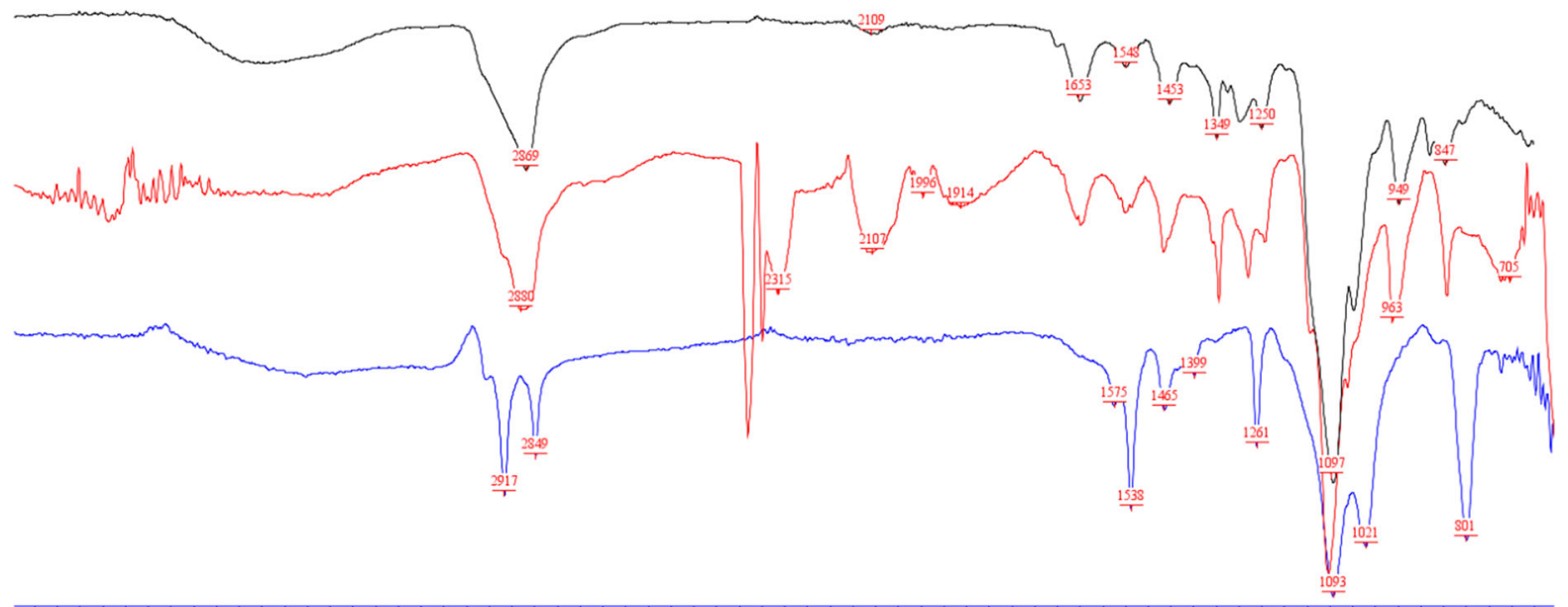

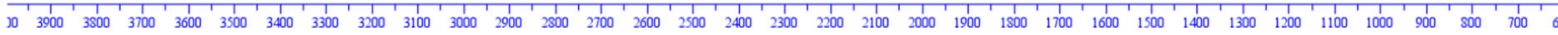

Fig. 1 FT-IR spectra: PEG-BFO NP (black), fNP-1 (red), fNP-2 (blue). (Color figure online) 
cells. Attempts of additional purification were not met with success. Detailed studies were thus carried out on functionalized harmonic nanoparticles fNP-2, resulting from copper-free click reaction.

Compound $\mathbf{8}$ was first assessed for its ability to inhibit prolyl-endopeptidase activity on the most relevant members of the prolyl-oligopeptidase family, both on human recombinant (hr) enzymes and on human lung cancer cells extracts (Table 1). Compound $\mathbf{8}$ was tested on hrPOP and hrFAP $\alpha$, as well as on the prolyl-exopeptidase dipeptidyl peptidase IV (hrDPPIV) to determine the selectivity toward endoproteolytic activity.

While compound 8 inhibited both hrFAP- $\alpha$ and hrPOP with Ki values of 0.055 and $0.12 \mu \mathrm{M}$, respectively, no significant inhibition was observed for human recombinant DPPIV. This observation suggests the specificity of compound $\mathbf{8}$ toward oligopeptidases displaying prolyl-endopeptidase activity.

The inhibition by compound $\mathbf{8}$ of cell-associated prolyl-endopeptidase activities was then evaluated on a cancer model composed of the three human A549, NCI-H596, and NCI-H520 lung-derived carcinoma cancer cells and the human lung-derived non-tumoral BEAS-2B epithelial cells (Fig. 2a). All cancer cells displayed significant enhanced endopeptidase activity compared to the non-tumoral BEAS2B cells. Compound 8 inhibited prolyl-endopeptidase activity only in tumor cells and not in the nontumoral cells, whereas no inhibition of prolylexopeptidase activity in these cells was observed (data not shown). In addition, when added to living cells, compound $\mathbf{8}$ associated with lung-derived A549 cancer cells, but not with non-tumoral BEAS-2B cells (Fig. 2b).

Based on these results, the targeted labeling of human lung cancer cells with fNP-2 was investigated using one tumoral (NCI-H520) and one non-tumoral (BEAS-2B) lines. PEGylated harmonic NPs (PEG-

Table 1 Kinetic characteristics for the inhibition of prolyloligopeptidases by compound 8 Human recombinant FAP- $\alpha$ (hrFAP- $\alpha$ ), DPPIV (hrDPPIV), and POP (hrPOP) were exposed to increasing concentrations $(5,10,50,200,500,1000,5000$,
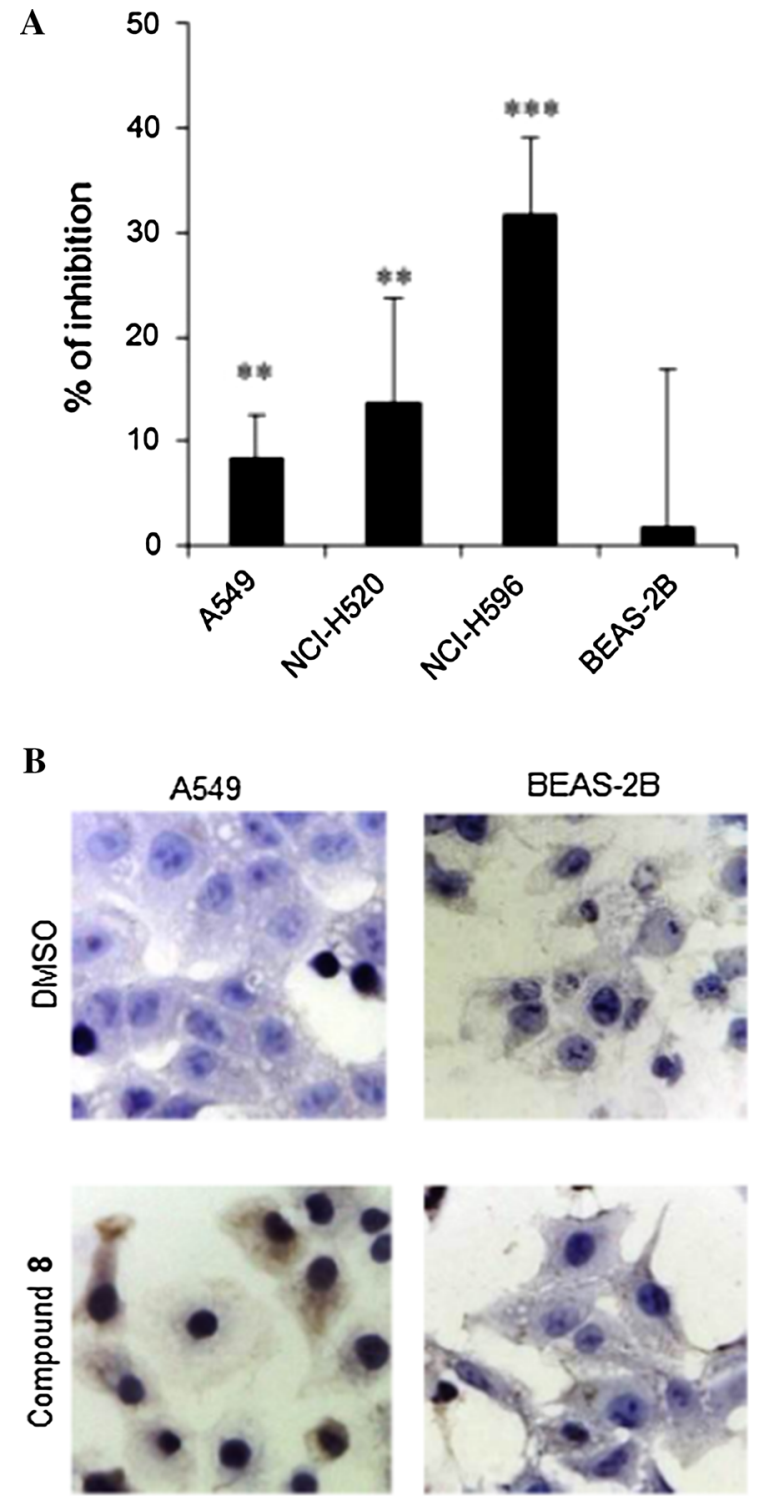

BFO NPs) were considered as negative controls. The cells were exposed to fNP-2, then labeled with a fluorescent probe for cell membranes, and the

and $10,000 \mathrm{nM}$ ) of compound $\mathbf{8}$, then to $50 \mu \mathrm{M}$ of the appropriate substrate (Z-Gly-Pro-AMC for hrFAP $\alpha$ and hrPOP, H-Gly-Pro-AMC for hrDPPIV) and the residual enzymatic activity was determined

\begin{tabular}{|c|c|c|c|c|c|c|}
\hline \multicolumn{3}{|c|}{$\operatorname{hrFAP} \alpha$} & \multicolumn{2}{|l|}{ hrDPPIV } & \multicolumn{2}{|l|}{ hrPOP } \\
\hline & $\mathrm{IC}_{50}(\mu \mathrm{M})$ & $\mathrm{K}_{\mathrm{i}}(\mu \mathrm{M})$ & $\mathrm{IC}_{50}(\mu \mathrm{M})$ & $\mathrm{K}_{\mathrm{i}}(\mu \mathrm{M})$ & $\mathrm{IC}_{50}(\mu \mathrm{M})$ & $\mathrm{K}_{\mathrm{i}}(\mu \mathrm{M})$ \\
\hline 8 & 0.315 & 0.055 & $>10$ & - & 0.58 & 0.12 \\
\hline
\end{tabular}

The half maximal inhibitory concentration $\left(\mathrm{IC}_{50}\right)$ and the inhibition constant $\left(\mathrm{K}_{i}\right)$ were calculated 
4Fig. 2 Compound $\mathbf{8}$ inhibits the prolyl-oligopeptidase activity of human lung cancer cells (a) and associates with lung human cancer cells (b). a The human lung-derived A549, NCI-H520, and NCI-H596 cancer cells and non-tumoral lung-derived BEAS-2B cells were pre-incubated with $10 \mu \mathrm{M}$ of compound 8 for $30 \mathrm{~min}$, then the residual enzymatic activity was determined using $50 \mu \mathrm{M}$ of Z-Gly-Pro-AMC and expressed as percent of inhibition by compound 8. Exposed cells were compared to cells exposed to solvent (DMSO) using a Student's $t$ test: $* * p<0.01 ; * * * p<0.001$. b Lung-derived cancer cells (A549) and non-tumoral cells (BEAS-2B) $(100,000$ cells/well) were exposed to $100 \mu \mathrm{M}$ compound 8 for $30 \mathrm{~min}$, then the association of this compound with the cells was assessed by adding a peroxidase-conjugated streptavidin. The binding of compound $\mathbf{8}$ in exposed cells and cells exposed to the vehicle (DMSO) was compared. Blue counterstain with hematoxylin; brown spots compound 3 detected by streptavidin. Magnification: $\times 400$. (Color figure online) harmonic NPs were revealed by detecting their SHG signal (excitation at $790 \mathrm{~nm}$ ) (Fig. 3).

In order to evaluate the specificity of the targeting, a competition assay was done, in which lung-derived NCI-H520 cancer cells were incubated with compound 8 alone prior to being exposed to fNP-2. Cells labeled with NPs were counted and the number of cells displaying association with the NPs was expressed as the percent ratio of positive cells to total cells in a microscopic field (Fig. 4).

Both cancer cells and non-tumoral cells were labeled with fNP-2, but the number of cancer cells associated with fNP-2 was significantly much higher than for non-tumoral cells. Moreover, in the competition assay the quantification of the association clearly
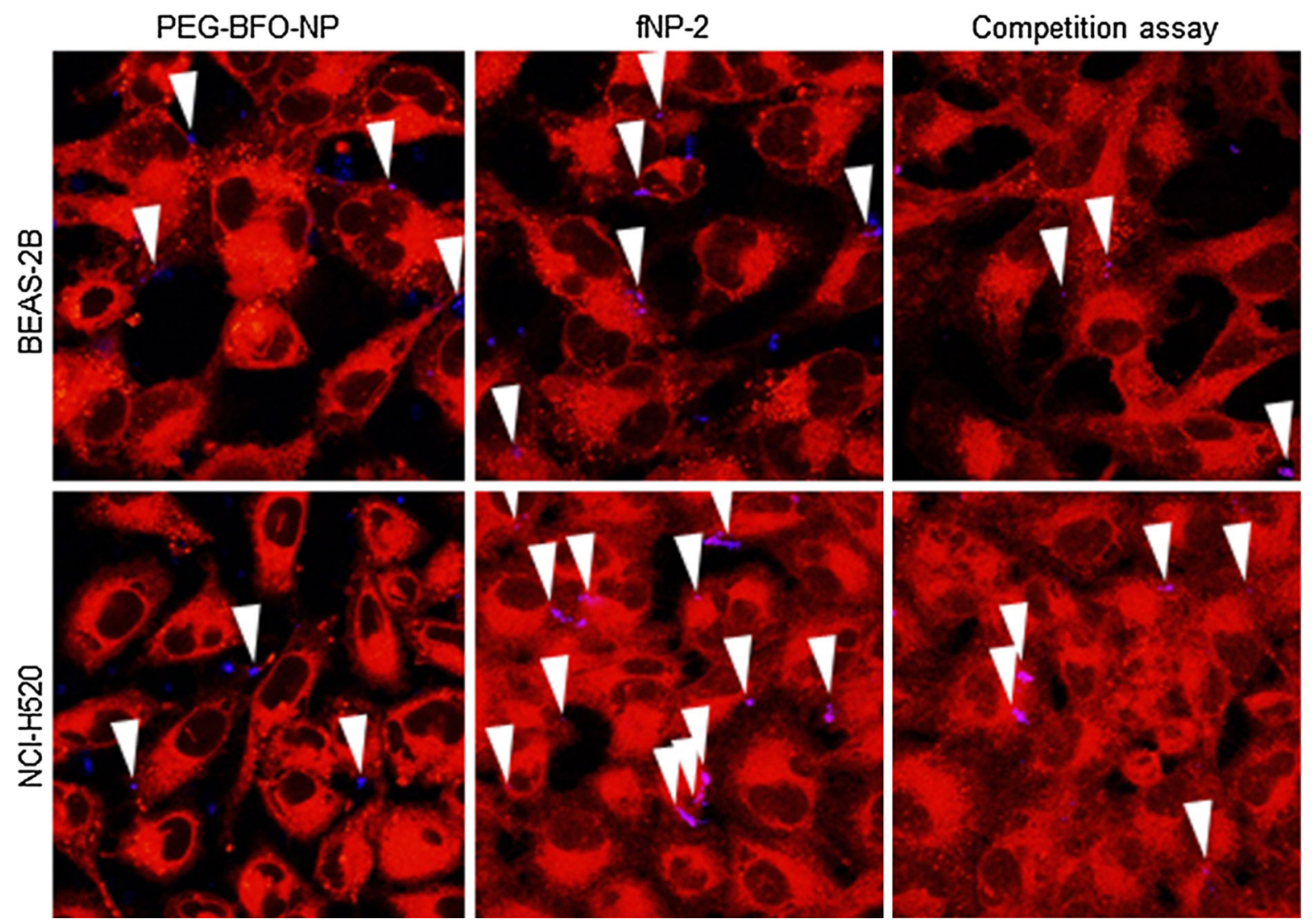

Fig. 3 Cancer cells labeling using fNP-2. Lung-derived NCIH520 (tumoral) and BEAS-2B (non-tumoral) cells (100,000 cells/well) were exposed for $30 \mathrm{~min}$ to $50 \mu \mathrm{g} / \mathrm{mL}$ of PEG-BFO $\mathbf{N P}$, to $50 \mu \mathrm{g} / \mathrm{mL}$ of fNP-2 or to $50 \mu \mathrm{g} / \mathrm{mL}$ of fNP-2 after $30 \mathrm{~min}$ pre-incubation with $100 \mu \mathrm{M}$ of compound 8
(Competition assay), then the cells were fixed and the cell membranes were labeled using the fluorescent probe FM1-43FX (red). SHG of NPs was detected by multiphoton microscopy (blue, those associated with cells are indicated with white arrows). Magnification: $\times 200$. (Color figure online) 


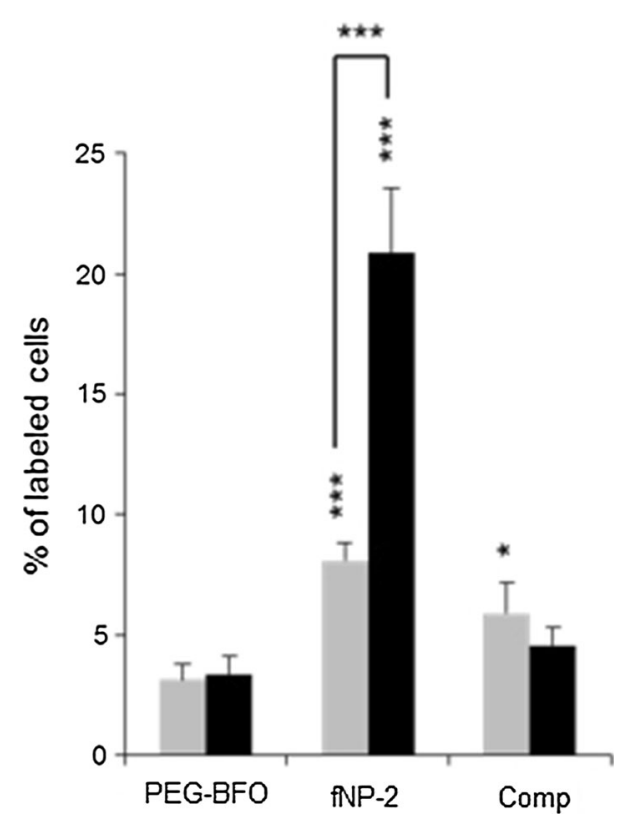

Fig. 4 Quantification of cells labeled with fNP-2. Human lungderived NCI-H520 (tumoral, black bars) and BEAS-2B (nontumoral, gray bars) cells were exposed to $25 \mu \mathrm{g} / \mathrm{mL}$ of PEGBFO NP, to $50 \mu \mathrm{g} / \mathrm{mL}$ of fNP-2 or to $25 \mu \mathrm{g} / \mathrm{mL}$ of fNP-2 after 30 min pre-incubation with $100 \mu \mathrm{M}$ of compound 8 (Comp). The number of labeled cells was expressed as the percent of the ratio of cells displaying association with the NPs to the total cells in a microscopy field (magnification $\times 200$ ). The percentages of cells labeled with PEG-BFO NP were compared to those of cells labeled with fNP-2, then tumoral cells were compared to non-tumoral cells using a Student's $t$ test: $* p<0.05 ; * * * p<0.001$

revealed that the binding was target-specific. These results suggest that harmonic BFO NPs can be efficiently transformed into labeling nanodevices targeting proteins expressed at the surface of cancer cells.

\section{Conclusion}

Here, we present a general approach for the functionalization of imaging NPs with low molecular weight tumor-specific targeting agents. In particular, copperfree click reaction allows highly efficient conjugation of alkynyl-containing ligands to PEGylated BFO NPs displaying surface reactive azido groups. The resulting nanoparticles combine imaging properties and specific recognition of cancer cell biomarkers offering new modalities for improved early cancer diagnosis, a presently unmet need (Zuo et al. 2007). Following the demonstration of the potential of BFO NPs for bioimaging and selective photointeraction (Staedler et al. 2014) and the study of their biological effect (Staedler et al. 2015), the present study demonstrates, for the first time, their ability to be converted into targeted imaging nanodevices. While the selectivity factor for the labeling of cancer cells vs non-tumoral cells need to be improved, the strategy illustrated herein can be easily transferred to other metal oxide NPs, thus enlarging the range of detection modalities. In addition, the use of a specific covalent inhibitor of cell membrane prolyl endopeptidases that can be further modified without affecting its affinity for the targeted enzymes, appears as an appealing methodology for targeting cancer- and tumor-associated cells.

Acknowledgments This work was supported by the European Commission FP7 NAMDIATREAM project (EU NMP4-LA2010-246479) and by the INTERREG IV NAOMI project. The authors thank MER Dr. Christine Wandrey for helpful discussions and access to analytical equipment. We also thank Mr. Anto Barisic and Dr. Pascal Miéville (NMR spectrometry service, ISIC, EPFL), Dr. Laure Menin and Mr. Francisco Sepulveda (MS service, ISIC, EPFL) for their technical help.

\section{References}

Ahmad P, Khandaker MU, Amin YM, Khan ZR (2015) Synthesis of boron nitride microtubes and formation of boron nitride nanosheets. Mater Manuf Processes 30(2):184-188. doi:10.1080/10426914.2014.952041

Arruebo M, Valladares M, Gonzalez-Fernadez A (2009) Antibody-conjugated nanoparticles for biomedical applications. J Nanomater. doi:10.1155/2009/439389

Bardhan R, Lal S, Joshi A, Halas NJ (2011) Theranostic nanoshells: from probe design to imaging and treatment of cancer. Acc Chem Res 44(10):936-946. doi:10.1021/ $\operatorname{ar} 200023 \mathrm{x}$

Baumner R, Bonacina L, Enderlein J, Extermann J, FrickeBegemann T, Marowsky G, Wolf JP (2010) Evanescent-field-induced second harmonic generation by noncentrosymmetric nanoparticles. Opt Express 18(22):23218-23225. doi:10.1364/OE.18.023218

Bonacina L (2012) Nonlinear nanomedicine: harmonic nanoparticles toward targeted diagnosis and therapy. Mol Pharm 10(3):783-792. doi:10.1021/mp300523e

Borcard F, Staedler D, Comas H, Juillerat FK, Sturzenegger PN, Heuberger R, Gonzenbach UT, Juillerat-Jeanneret L, Gerber-Lemaire S (2012) Chemical functionalization of bio-ceramics to enhance endothelial cells adhesion for tissue engineering. J Med Chem 55:7988-7997. doi:10. 1021/jm301092r 
Brennen WN, Isaacs JT, Denmeade SR (2012) Rationale behind targeting fibroblast activation protein-expressing carcinoma-associated fibroblasts as a novel chemotherapeutic strategy. Mol Cancer Ther 11:257-266. doi:10.1158/15357163.MCT-11-0340

Cer RZ, Mudunuri U, Stephens R, Lebeda FJ (2009) IC50-to-Ki: a web-based tool for converting IC50 to $\mathrm{Ki}$ values for inhibitors of enzyme activity and ligand binding. Nucleic Acid Res 37:W441-445. doi:10.1093/nar/gkp253

Chinen AB, Guan CM, Ferrer JR, Barnaby SN, Merkel TJ, Mirkin CA (2015) Nanoparticle probes for the detection of cancer biomarkers, cells, and tissues by fluorescence. Chem Rev. doi:10.1021/acs.chemrev.5b00321

Cohen BE (2010) Biological imaging: beyond fluorescence. Nature 467:407-408. doi:10.1038/467407a

Čulić-Viskota J, Dempsey WP, Fraser SE, Pantazis P (2012) Surface functionalization of barium titanate SHG nanoprobes for in vivo imaging in zebrafish. Nat Protoc 7:1590-1607. doi:10.1038/nprot.2012.081

Danhier F, Le Breton A, Préat V (2012) RGD-based strategies to target alpha(v)beta(3) integrin in cancer therapy and diagnosis. Mol. Pharm 9:2961-2973. doi:10.1021/ mp3002733

Dempsey WP, Fraser SE, Pantazis P (2012) SHG nanoprobes: advancing harmonic imaging in biology. Bioesssays 34:351-360. doi:10.1002/bies.201100106

Desgrosellier JS, Cheresh DA (2010) Integrins in cancer: biological implications and therapeutic opportunities. Nat Rev Cancer 10(1):9-22. doi:10.1038/nrc2748

Erathodiyil N, Ying JY (2011) Functionalization of inorganic nanoparticles for bioimaging applications. Acc Chem Res 44(10):925-935. doi:10.1021/ar2000327

Extermann J, Bonacina L, Cuña E, Kasparian C, Mugnier Y, Feurer T, Wolf JP (2009) Nanodoublers as deep imaging markers for multiphoton microscopy. Opt Express 17(17):15342-15349. doi:10.1364/OE.17.015342

Hsieh CL, Grange R, Pu Y, Psaltis D (2010a) Three-dimensional harmonic holographic microscopy using nanoparticles as probes for cell imaging: erratum. Opt Express 18(4):3456-3457. doi:10.1364/OE.18.003456

Hsieh CL, Pu Y, Grange R, Laporte G, Psaltis D (2010b) Imaging through turbid layers by scanning the phase conjugated second harmonic radiation from a nanoparticle. Opt Express 18(20):20723-20731. doi:10.1364/OE.18. 020723

Juillerat-Jeanneret L, Gerber-Lemaire S (2009) The prolylaminodipeptidases and their inhibitors as therapeutic targets for fibrogenic disorders. Mini Rev Med Chem 9(2):215-226. doi:10.2174/138955709787316100

Kairdolf BA, Smith AM, Stokes TH, Wang MD, Young AN, Nie S (2013) Semiconductor quantum dots for bioimaging and biodiagnostic applications. Annu Rev Anal Chem 6:143162. doi:10.1146/annurev-anchem-060908-155136

Lawandi J, Gerber-Lemaire S, Juillerat-Jeanneret L, Moitessier $\mathrm{N}$ (2010) Inhibitors of prolyl oligopeptidases for the therapy of human diseases: defining diseases and inhibitors. J Med Chem 53:3423-3438. doi:10.1021/jm901104g

Le Xuan L, Zhou C, Slablab A, Chauvat D, Tard C, Perruchas S, Gacoin T, Villeval P, Roch JF (2008) Photostable secondharmonic generation form a single $\mathrm{KTiOPO}_{4}$ nanocrystal for nonlinear microscopy. Small 4:1332-1336. doi:10. 1002/smll.200701093

Magouroux T, Extermann J, Hoffmann P, Mugnier Y, Le Dantec R, Jaconi ME, Kasparian C, Ciepielewski D, Bonacina L, Wolf JP (2012) High-speed tracking of murine cardiac stem cells by harmonic nanodoublers. Small 8:2752-2756. doi:10.1002/smll.201200366

Meyer T, Schmitt M, Dietzek B, Popp J (2013) Accumulating advantages, reducing limitations: multimodal nonlinear imaging in biomedical sciences - the synergy of multiple contrast mechanisms. J. Biophoton 6:887-904. doi:10. 1002/jbio.201300176

Pantazis P, Maloney J, Wu D, Fraser SE (2010) Second harmonic generation (SHG) nanoprobes for in vivo imaging. Proc Natl Acad Sci USA 107(33):14535-14540. doi:10. 1073/pnas. 1004748107

Passemard S, Staedler D, Ucnova L, Schneiter GS, Kong P, Bonacina L, Gerber-Lemaire S (2013) Convenient synthesis of heterobifunctional poly(ethylene glycol) suitable for the functionalization of iron oxide nanoparticles for biomedical applications. Bioorg Med Chem 23:5006-5010. doi:10.1016/j.bmcl.2013.06.037

Poplawski S, Lai JH, Li Y, Jin Z, Liu Y, Wu W, Wu Y, Zhou Y, Sudmeier JL, Sanford DG, Bachovchin WW (2013) Identification of selective and potent inhibitors of fibroblast activation protein and prolyl oligopeptidase. J Med Chem 56:3467-3477. doi:10.1021/jm400351a

Powers JJ, Favor DA, Rankin T, Sharma R, Pandit C, Jeganathan A, Maiti SN (2009) Synthesis of methyl-, fluoro-, and chloro-substituted 6-hydroxyisoindolin-1-ones. Tetrahedron Lett 50:1267-1269. doi:10.1016/j.tetlet.2008.12. 099

Rostovtsev VV, Green LG, Fokin VV, Sharpless KB (2002) A stepwise huisgen cycloaddition process: copper(I)-catalyzed regioselective "ligation" of azides and terminal alkynes. Angew Chem Int Ed 41:2596-2599. doi:10.1002/ 1521-3773(20020715)41:14

Schwung S, Rogov A, Clarke G, Joulaud C, Magouroux T, Staedler D, Passemard S, Jüstel T, Badie L, Galez C, Wolf JP, Volkov Y, Prina-Mello A, Gerber-Lemaire S, Rytz D, Mugnier Y, Bonacina L, Le Dantec R (2014) Nonlinear optical and magnetic properties of $\mathrm{BiFeO}_{3}$ harmonic nanoparticles. J Appl Phys 116:114306. doi:10.1063/1. 4895836

Sletten EM, Bertozzi CR (2011) From mechanism to mouse: a tale of two bioorthogonal reactions. Acc Chem Res 44(9):666-676. doi:10.1021/ar200148z

Staedler D, Magouroux T, Hadji R, Jouloud C, Extermann J, Schwung S, Passemard S, Kasparian C, Clarke G, Gerrmann M, Le Dantec R, Mugnier Y, Rytz D, Ciepielewski D, Galez C, Gerber-Lemaire S, Juillerat-Jeanneret L, Bonacina L, Wolf JP (2012) Harmonic nanocrystals for bio-labeling: a survey of optical properties and biocompatibility. ACS Nano 6:2542-2549. doi:10.1021/ nn204990n

Staedler D, Magouroux T, Passemard S, Schwung S, Dubled M, Schneiter GS, Rytz D, Gerber-Lemaire S, Bonacina L, Wolf JP (2014) Deep UV generation and direct DNA photo-interaction by harmonic nanoparticles in labelled samples. Nanoscale 6:2929-2936. doi:10.1039/c3nr05897b 
Staedler D, Passemard S, Magouroux T, Rogov A, Maguire CM, Mohamed BM, Schwung S, Rytz D, Jüstel T, Hwu S, Mugnier Y, Le Dantec R, Volkov Y, Gerber-Lemaire S, Prina-Mello A, Bonacina L, Wolf JP (2015) Cellular uptake and biocompatibility of bismuth ferrite harmonic advanced nanoparticles. Nanomedicine NBM 11:815-824. doi:10.1016/j.nano.2014.12.018

Sun C, Sze R, Zhang MQ (2006) Folic acid-PEG conjugated superparamagnetic nanoparticles for targeted cellular uptake and detection by MRI. J Biomed Mater Res A 78A:550-557. doi:10.1002/jbm.a.30781

Wang Y, Gu H (2015) Core-shell-type magnetic mesoporous silica nanocomposites for bioimaging and therapeutic agent delivery. Adv Mater 27:576-585. doi:10.1002/adma. 201401124

Wen J, Xu Y, Li H, Lu A, Sun S (2015) Recent applications of carbon nanomaterials in fluorescence biosensing and bioimaging. Chem Commun 51:11346-11358. doi:10. 1039/c5cc02887f

Wolfbeis OS (2015) An overview of nanoparticles commonly used in fluorescent bioimaging. Chem Soc Rev 44:4743-4768. doi:10.1039/c4cs00392f

Yao J, Yang M, Duan Y (2014) Chemistry, biology and medicine of fluorescent nanomaterials and related systems: new insights into biosensing, bioimaging, genomics, diagnostics and therapy. Chem Rev 114:6130-6178. doi:10.1021/ cr200359p

Zhou J, Liu Q, Feng W, Sun Y, Li F (2015) Upconversion luminescent materials: advances and applications. Chem Rev 115(1):395-465. doi:10.1021/cr400478f

Zuo L, Wei WC, Morris M, Wei JC, Gorbounov M, Wei CM (2007) New technology and clinical applications of nanomedicine. Med Clin N Am 91:845-862 